\title{
ST8SIA1 inhibits the proliferation, migration and invasion of bladder cancer cells by blocking the JAK/STAT signaling pathway
}

\author{
SHENGJIN YU ${ }^{1 *}$, SHIDAN WANG ${ }^{2 *}$, XIAOXIN SUN ${ }^{2,3^{*}}$, YINSHUANG WU ${ }^{2}$, \\ $\mathrm{JUN}_{\mathrm{ZHAO}}{ }^{4}$, JUNQIANG LIU ${ }^{4}$, DEYONG YANG $^{4}$ and YU JIANG ${ }^{1}$ \\ ${ }^{1}$ Institute of Molecular Medicine, Medical College of Eastern Liaoning University, Dandong, \\ Liaoning 118000; ${ }^{2}$ Department of Biochemistry and Molecular Biology, Institute of Glycobiology; \\ ${ }^{3}$ College of Integrative Medicine, Dalian Medical University, Dalian, Liaoning 116044; ${ }^{4}$ Department of Urology, \\ First Affiliated Hospital of Dalian Medical University, Dalian, Liaoning 116011, P.R. China
}

Received October 17, 2020; Accepted May 7, 2021

DOI: 10.3892/ol.2021.12997

\begin{abstract}
Bladder cancer (BLCA) is the most common malignant tumor of the urinary system, with distant metastasis of the tumor being the main cause of death. The identification of an effective biomarker may provide a novel direction for BLCA diagnosis and treatment. The aim of the present study was to screen the BLCA-related genes involved in sialyl transferase (ST) dysregulation and to investigate the functional mechanisms of $\alpha-2,8-\mathrm{ST} 1$ (ST8SIA1) in BLCA cells. Data from The Cancer Genome Atlas and Gene Expression Profiling Interactive Analysis databases suggested that the mRNA expression levels of ST8SIA1 were decreased in BLCA tissues compared with normal tissues, which was also demonstrated using immunohistochemistry and western blot analysis. The expression levels of ST8SIA1 were negatively associated with the pathological grade and invasiveness of BLCA. Western blot analysis revealed that the expression levels of ST8SIA1 were lower in BLCA cell lines than in a normal urothelial cell line. CCK-8, flow cytometry, wound healing, colony formation and Transwell assays indicated that ST8SIA1 overexpression attenuated the proliferation, migration and invasion of T24 and 5637 BLCA cells. Further experiments revealed that ST8SIA1 could inhibit the phosphorylation of Janus kinase (JAK)2 and STAT3, as well as decrease the expression levels of JAK/STAT
\end{abstract}

Correspondence to: Professor Yu Jiang, Institute of Molecular Medicine, Medical College of Eastern Liaoning University, 116 Linjiang Back Street, Dandong, Liaoning 118000, P.R. China E-mail: jiangyu6567@163.com

Professor Deyong Yang, Department of Urology, First Affiliated Hospital of Dalian Medical University, 222 Zhongshan Road, Dalian, Liaoning 116011, P.R. China

E-mail: yangdeyong@dmu.edu.cn

${ }^{*}$ Contributed equally

Key words: sialyl transferase, $\alpha-2,8-\mathrm{ST} 1$, bladder cancer, growth, migration, invasion, JAK/STAT pathway-targeting signal molecules, including MMP2, proliferating cell nuclear antigen, cyclin D1 and Bcl2 in two BLCA cell lines. In conclusion, to the best of our knowledge, the present study was the first to indicate that the antitumor effect of ST8SIA1 in BLCA cells was mediated by the JAK/STAT signaling pathway, and the results provided a novel target for the diagnosis and treatment of BLCA.

\section{Introduction}

Bladder cancer (BLCA) is the tenth most common cancer type worldwide, with an estimated 549,000 new cases and 200,000 deaths each year according to the Global Cancer Statistics 2018 (1). BLCA is more common in men than in women, with the morbidity and mortality rate in men being four times higher than that in women worldwide (1). Transitional cell carcinoma is the most common pathological subtype of BLCA, accounting for $\sim 90 \%$ of all BLCA cases (2). Squamous cell carcinoma and adenocarcinoma are ranked second and third, respectively (2). BLCA can be divided into two types according to degree of invasiveness: Non-muscle invasive BLCA (NMIBC) and muscle invasive BLCA (MIBC) (3). NMIBC does not pose a major threat to the lives of the patients; however, NMIBC has a high recurrence rate, with a small number of patients progressing to invasive $\operatorname{BLCA}(2,4)$. MIBC is invasive and has a high mortality rate (4). Therefore, it is necessary to identify novel molecular targets for the diagnosis and treatment of BLCA.

Protein glycosylation is a common post-translational modification regulated by glycosyltransferases and glycosidases present in the endoplasmic reticulum-Golgi complex (5). The two most common types of glycosylation are O-linked glycosylation and N-linked glycosylation (6). Changes in the degree of glycosylation are caused by the overexpression of glycoproteins carrying certain carbohydrate chains, an increase or decrease in the levels of nucleotide donors, and changes in the expression of glycosyltransferases and glycosidases (7). Glycosylation serves a key role in a number of important biological processes of tumors, including cell adhesion, metastasis, cell signal transduction and cell metabolism $(8,9)$. Sialylation is one of the important pathways of glycosylation modification and is a typical protein terminal modification 
that mediates important biological functions (10). It has been demonstrated that abnormal sialylation is closely associated with malignant brain tumors and multiple myeloma, and is usually accompanied by changes in the expression levels of sialyl transferases (STs) $(11,12)$.

The human ST family consists of 20 STs that catalyze the binding of sialic acid of CMP-Neu5Ac to the terminal glycosyl groups of the glycoconjugates (13-15). According to the different types of glycosidic bonds formed, salivary STs are further divided into 3 types: ST3 $\beta$-galactoside $\alpha$-2,3-ST (ST3GAL)1-6, ST6 $\beta$-galactoside $\alpha-2,6-$ ST1-2 and $\alpha-2,8-S T 1$ (ST8SIA1)-6 (16). ST8SIA1 is a member of the ST family involved in the production of gangliosides (17). The abnormal expression of ST8SIA1 has been demonstrated to influence the metastasis of triple-negative breast cancer (18); however, to the best of our knowledge, the role of this enzyme in BLCA remains unknown.

In the present study, differentially expressed glycosyltransferases and their expression profile were evaluated based on the data obtained from The Cancer Genome Atlas (TCGA) and Gene Expression Profiling Interactive Analysis (GEPIA) databases. The subsequent experiments performed in the present study aimed to investigate the association between ST8SIA1 expression and the clinicopathological characteristics of patients with BLCA, as well as to reveal the effect and regulatory mechanism of ST8SIA1 on the proliferation, migration and invasion of BLCA cells. The downregulation and antitumor role of ST8SIA1 in BLCA may provide a new strategy to diagnose and treat BLCA.

\section{Materials and methods}

Patient samples. A total of 136 BLCA tissue and adjacent normal tissue samples ( $>5 \mathrm{~cm}$ away from the tumor edge) were collected from randomly selected patients undergoing surgical resection between May 2008 and July 2013 at The First Affiliated Hospital of Dalian Medical University (Dalian, China). After surgical resection, all samples were routinely processed and paraffin-embedded. The inclusion criterion was primary and metastatic BLCA tissues of patients. Tissue specimens from patients who received radiotherapy or chemotherapy before surgical resection were excluded. The age range of the patients was 34-82 years with a mean age of 58.8 years. The ratio of male to female was 97:39. Tumors were staged according to the 7th Edition of the American Joint Committee on Cancer (19). Of the 136 BLCA tissue, 39 were determined as early stage (I/II) and 97 as late stage (III/IV). The present study was approved by the Institutional Research Ethics Committee of the First Affiliated Hospital of Dalian Medical University (approval no. LCKY2015-08; Dalian, China), and written informed consent was provided by the patients with BLCA who underwent surgery.

Cell culture. SV-HUC-1 normal bladder epithelial cell, 5637 and T24 BLCA cell lines were purchased from The Cell Bank of Type Culture Collection of The Chinese Academy of Sciences. SV-HUC-1 normal bladder epithelial cells were cultured in F12/DMEM (Thermo Fisher Scientific, Inc.) supplemented with 10\% FBS (Thermo Fisher Scientific, Inc.). The 5637 and T24 BLCA cell lines were cultured inRPMI-1640 medium (Thermo Fisher Scientific, Inc.) supplemented with 10\% FBS
(Thermo Fisher Scientific, Inc.). All cell cultures were supplemented with $1 \%$ penicillin/streptomycin, and cells were incubated with $5 \% \mathrm{CO}_{2}$ at $37^{\circ} \mathrm{C}$.

Identification of differentially expressed glycosyltransferases. TCGA (https://cancergenome.nih.gov/; Project ID:TCGA-BLCA) project provided $\mathrm{mRNA}$ expression profile data on 408 BLCA cases: 433 samples, including 19 normal and 414 BLCA samples. Some patients provided both cancer tissue and adjacent normal tissue and some patients provided $>2$ cancer tissues. Therefore, the number of patient cases was less than the tissue samples obtained from the TCGA database. The 'edgeR' package (http://www.bioconductor. org/help/search/index.html?q=edger/; release number 3.13; Bioconductor) in R software (https://www.r-project.org/; release number 3.6.1) was used to identify the differentially expressed mRNAs of glycosyltransferases in BLCA tissues compared with normal bladder tissues. The following thresholds were used to identify significant differentially expressed genes: False discovery rate $(F D R)<0.001$ and $\mid \log _{2}$ (fold change) $\mid>2$. After screening of differentially expressed genes, the differentially expressed gene ID were obtained. The gene ID were annotated using ENSEMBL (https://www.ensembl.org/) to get the differentially expressed gene symbol. Then, the expression levels of ST8SIA1 in BLCA and normal tissue were assessed based on the data obtained from GEPIA (http://gepia.cancer-pku.cn/).

Immunohistochemical staining. BLCA and adjacent normal tissue were fixed with $4 \%$ paraformaldehyde at room temperature for $24 \mathrm{~h}$. After paraffin embedding, $4 \mu \mathrm{m}$-thick sections were cut and mounted onto slides. Next, slides were deparaffinized with xylene, rehydrated by a series of graded alcohol solutions as follows: $100,100,95,85$ and $75 \%$. The antigen was retrieved with $10 \mathrm{mM}$ sodium citrate buffer at $95^{\circ} \mathrm{C}$ for $20 \mathrm{mi}$ and immersed in $3 \%$ hydrogen peroxide in methanol at room temperature for 15 min to block the endogenous peroxidase activity. The slides were washed with PBS twice, blocked with $5 \%$ goat serum (Beijing Zhong Shan-Golden Bridge Biological Technology Co., Ltd.) at room temperature for $20 \mathrm{~min}$ and incubated with a primary anti-ST8SIA1 antibody (1:80; cat. no. 24918-1-AP; ProteinTech Group, Inc.) at room temperature for $1 \mathrm{~h}$. Following washing with PBS, the PBS surrounding the tissue was wiped dry and the samples were incubated with a secondary horseradish peroxidase (HRP)-conjugated IgG antibody (1:100; cat. no. sc-2357; Santa Cruz Biotechnology, Inc.) at room temperature for $45 \mathrm{~min}$. The sections were then treated with 3,3'-diaminobenzidine at room temperature for $30 \mathrm{sec}$, counterstained with hematoxylin at room temperature for $5 \mathrm{~min}$, dried, sealed with a neutral gum and observed under a light microscope. The immunostaining intensity was then evaluated. The immunostaining for ST8SIA1 expression was scored using '-', '+', '++' and '+++', to indicate a positive staining percentage of $<5,5-25,25-50$ and $>50 \%$, respectively. All specimens were examined by 2 pathologists of The First Affiliated Hospital of Dalian Medical University (Dalian, China), who were blinded to the clinical data.

Cell transfection. T24 and 5637 cells were transfected with the recombinant pcDNA3.1/ST8SIA1 or mock vectors. Non-transfected and mock vector transfected cells were 
used as the control. The pcDNA3.1/ST8SIA1 and mock vectors were synthesized by Public Protein/Plasmid Library (http://www.geneppl.com/index.php; pcDNA3.1/ST8SIA1, cat. no. BC046158; mock vector, cat. no. V790-20). Cells were transfected with a mixture of $5 \mu \mathrm{g}$ plasmids and $10 \mu \mathrm{l}$ Lipofectamine $^{\circledR} 2000$ transfection reagent (Thermo Fisher Scientific, Inc.) at $37^{\circ} \mathrm{C}$ for $7 \mathrm{~h}$. To select a stable population of transfected cells, the culture medium was replaced with complete medium containing $600 \mathrm{mg} / \mathrm{ml} \mathrm{G} 418$ (Merck KGaA) after $48 \mathrm{~h}$. After 2 months of screening with $300 \mathrm{mg} / \mathrm{ml}$ G418, two cell lines stably expressing ST8SIA1 (ST8SIA1-1 and ST8SIA1-2) were established. The modified expression was confirmed by reverse transcription-quantitative PCR (RT-qPCR) and western blotting.

$R T-q P C R$. Total RNA was extracted from the tissue samples and cultured cells using TRIzol ${ }^{\circledR}$ reagent (Thermo Fisher Scientific, Inc.) according to the manufacturer's protocol. RNA was subjected to reverse transcription to generate cDNA using a PrimeScript RT reagent kit (Takara Bio, Inc.) for 2 min at $42^{\circ} \mathrm{C}$, $15 \mathrm{~min}$ at $37^{\circ} \mathrm{C}$ and $5 \mathrm{sec}$ at $85^{\circ} \mathrm{C}$ and stored at $-20^{\circ} \mathrm{C}$ and amplified by subsequent qPCR using a qPCR SYBR GreenSuperMix (TransGen Biotech Co., Ltd.). The amplification conditions were as follows: $94^{\circ} \mathrm{C}$ for $30 \mathrm{sec}$, followed by $94^{\circ} \mathrm{C}$ for $5 \mathrm{sec}$ and $60^{\circ} \mathrm{C}$ for $34 \mathrm{sec}$ for 40 cycles. Relative changes in gene expression were analyzed using the $2^{-\Delta \Delta C q}$ method (20). GAPDH was used as an internal control. Specific primers for GAPDH and ST8SIA1 were purchased from Shanghai GenePharma Co., Ltd. The primer sequences used were as follows: ST8SIA1 forward, 5'-CATTGAAGAAATGCGCGGTGG-3' and reverse, 5'-GTTCTGAAACCTTTGCCGAATTATG-3'; GAPDH forward, 5'-TCCAAAATCAAGTGGGGCGA-3' and reverse, 5'-AAATGAGCCCCAGCCTTCTC-3'.

Western blot analysis. Total protein was extracted from the cultured cells and specimens using RIPA buffer (Beyotime Institute of Biotechnology) and PMSF (dilution, 1:100; Beyotime Institute of Biotechnology). A bicinchoninic acid assay kit (Beyotime Institute of Biotechnology) was used for quantification. Equal amounts of protein (30 $\mu \mathrm{g} /$ lane) were separated using $12 \%$ SDS-PAGE and transferred onto PVDF membranes (Pall Life Sciences). The membranes were blocked at room temperature for $2 \mathrm{~h}$ with $5 \%$ fat-free milk prepared in 1XTris-Buffered Saline, $0.1 \%$ Tween ${ }^{\circledR} 20$ Detergent (TBST). Western blot analysis was performed using phosphorylated (p-) STAT3 (dilution, 1:500; cat. no. 39596; ProteinTech Group, Inc.), STAT3 (dilution, 1:500; cat. no. AP0366; Bioworld Technology, Inc.), ST8SIA1 (dilution, 1:500; cat. no. 24918-1-AP; ProteinTech Group, Inc.), Janus kinase 2 (JAK2; dilution, 1:500; cat. no. 17670-1-AP; ProteinTech Group, Inc.), p-JAK2 (dilution, 1:500; cat. no. AP0531; ABclonal Biotech Co., Ltd.), cyclin D1 (dilution, 1:500; cat. no. 26939-1-AP; ProteinTech Group, Inc.), MMP2 (dilution, 1:500; cat. no. 10373-2-AP; ProteinTech Group, Inc.), proliferating cell nuclear antigen (PCNA; dilution, 1:500; cat. no. 10205-2-AP; ProteinTech Group, Inc.), Bcl2 (dilution, 1:500; cat. no. 12789-1-AP; ProteinTech Group, Inc.) and GAPDH (dilution, 1:500; cat. no. 10494-1-AP; ProteinTech Group, Inc.) antibodies. The membranes were incubated with primary antibodies at $4^{\circ} \mathrm{C}$ overnight. After three washes with TBST, the membranes were incubated with a horseradish peroxidase-conjugated goat anti-rabbit secondary antibody (dilution, 1:5,000; cat. no. SA00001-2; ProteinTech Group, Inc.) at room temperature for $1 \mathrm{~h}$. The immunoreactivity was detected using an electrochemiluminescence kit (Advansta, Inc.) and processed using Image Lab software v.5.2 (Bio-Rad Laboratories, Inc.).

Cell counting Kit-8(CCK-8).Cell proliferation was determined using aCCK-8 assay (Dojindo Molecular Technologies, Inc.). BLCA cells were seeded into a 96-well plate at a density of $5 \times 10^{3}$ cells per well in triplicate. Cells were incubated at $37^{\circ} \mathrm{C}$ for $12,24,36$ or $48 \mathrm{~h}$, and $10 \mu \mathrm{lCCK}-8$ reagent was added into each well. Cells were incubated at $37^{\circ} \mathrm{C}$ with $5 \% \mathrm{CO}_{2}$ for $2 \mathrm{~h}$. A microplate reader (Thermo Fisher Scientific, Inc.) was used to measure the optical density values at $450 \mathrm{~nm}$.

Cell colony formation assay. BLCA cells in the logarithmic growth phase were digested into a single-cell suspension. Cells were seeded into 6-well culture plates (Corning, Inc.) at a density of 200 cells per well and incubated at $37^{\circ} \mathrm{C}$ with $5 \% \mathrm{CO}_{2}$ for 14 days. Following three washes with PBS, cells were fixed with paraformaldehyde (4\%) at room temperature for $15 \mathrm{~min}$ and stained with $0.1 \%$ crystal violet at room temperature for $30 \mathrm{~min}$. The colonies were imaged using a light optical microscope and the number of colonies of $>50$ cells was counted using ImageJ software v.4.0 (National Institutes of Health).

Flow cytometry. T24 and 5637 cells were collected as a single cell suspension and fixed with $75 \%$ alcohol at $4{ }^{\circ} \mathrm{C}$ overnight. The cells were centrifuged for $5 \mathrm{~min}$ at $1,000 \mathrm{x}$ g at room temperature and then washed with ice-cold PBS. Cells were stained by incubation with propidium iodide $(50 \mu \mathrm{g} / \mathrm{ml}$; Beyotime Institute of Biotechnology) combined with RNase A $(50 \mu \mathrm{g} / \mathrm{ml}$; Beyotime Institute of Biotechnology) for $30 \mathrm{~min}$ at $37^{\circ} \mathrm{C}$. Cells were detected using a flow cytometer (Accuri C6 Cytometer; BD Biosciences) and then analyzed with FlowJo software v.10.2 (TreeStar, Inc.). Signals were acquired from at least $1 \times 10^{6}$ cells per sample.

Wound healing assay. Cell migration was analyzed using a wound healing assay. Non-transfected T24 or 5637, mock, ST8SIA1-1 and ST8SIA1-2 cells $\left(2.5 \times 10^{6}\right)$ were respectively transferred to a six-well plate and allowed to grow to $100 \%$ confluence in complete medium. A $200-\mu 1$ sterile pipette tip was used to scratch a gap through the monolayer. The cellular debris was dislodged by washing with PBS thrice. The cells were then washed and imaged under a light microscope at a magnification of $\mathrm{x} 10$. Following cell culture with the serum-free medium for $12 \mathrm{~h}$, the same areas were imaged again. Cell mobility was assessed by calculating the remaining open area of the wound using ImageJ software v.4.0 (National Institutes of Health) and analyzed with the following formula: (Width 0 h-Width 12 h)/Width $0 \mathrm{~h}$ x100\%.

Transwell migration and invasion assay. A total of $\sim 2 \times 10^{4}$ cells in $150 \mu 1$ RPMI-1640 medium without FBS were added to the upper compartment of a 24-well Transwell chamber (pore size, $8.0 \mu \mathrm{m}$; diameter, $6.5 \mathrm{~mm}$; Corning, Inc.), and $500 \mu \mathrm{l}$ RPMI-1640 medium with $20 \%$ FBS was added to the lower compartment. Following incubation at $37^{\circ} \mathrm{C}$ for $48 \mathrm{~h}$ in a $5 \% \mathrm{CO}_{2}$ incubator, 
A

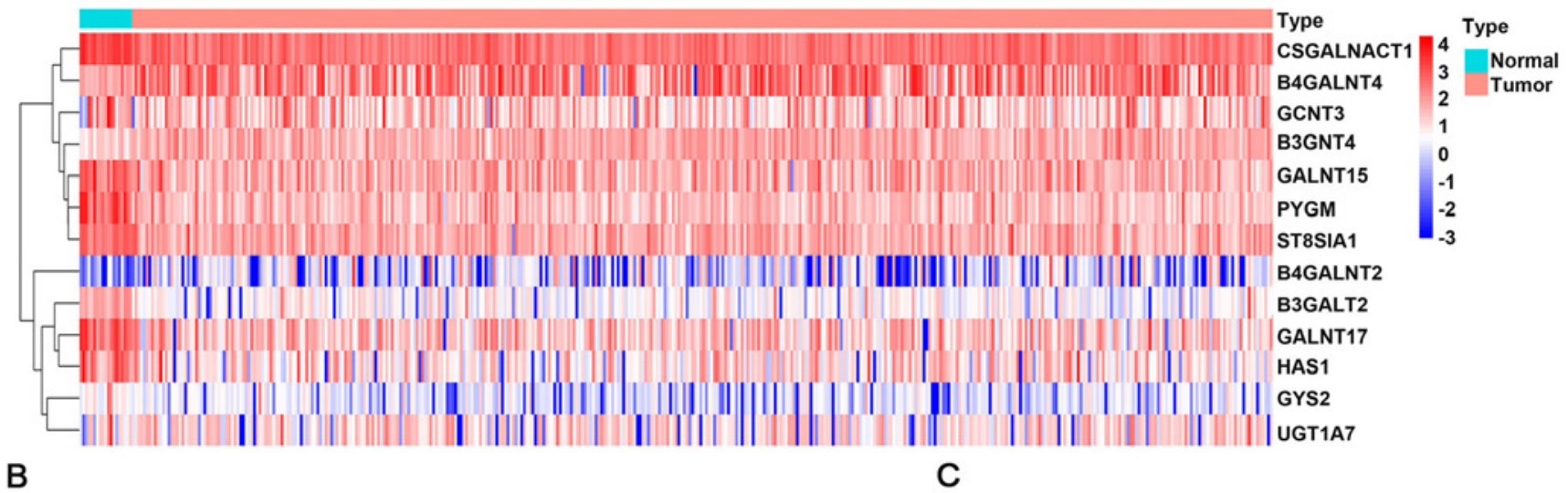

Volcano

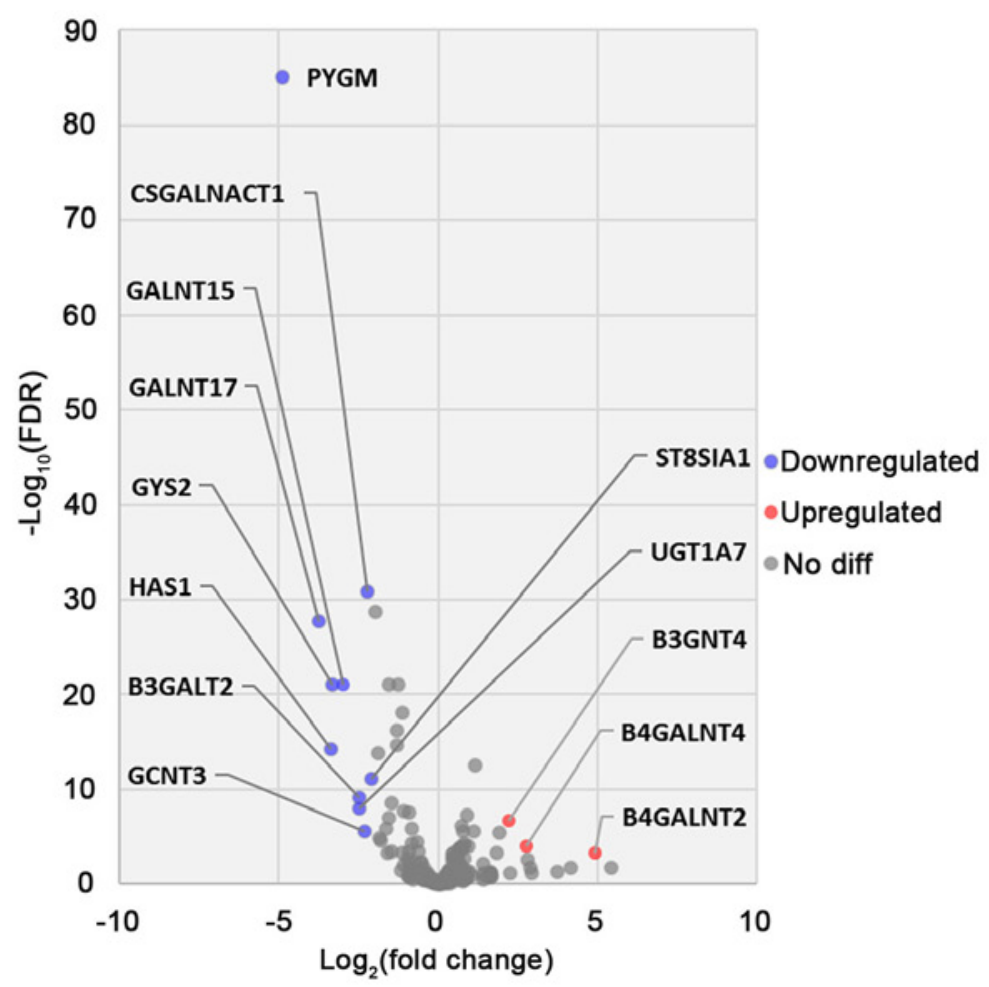

ST8SIA1

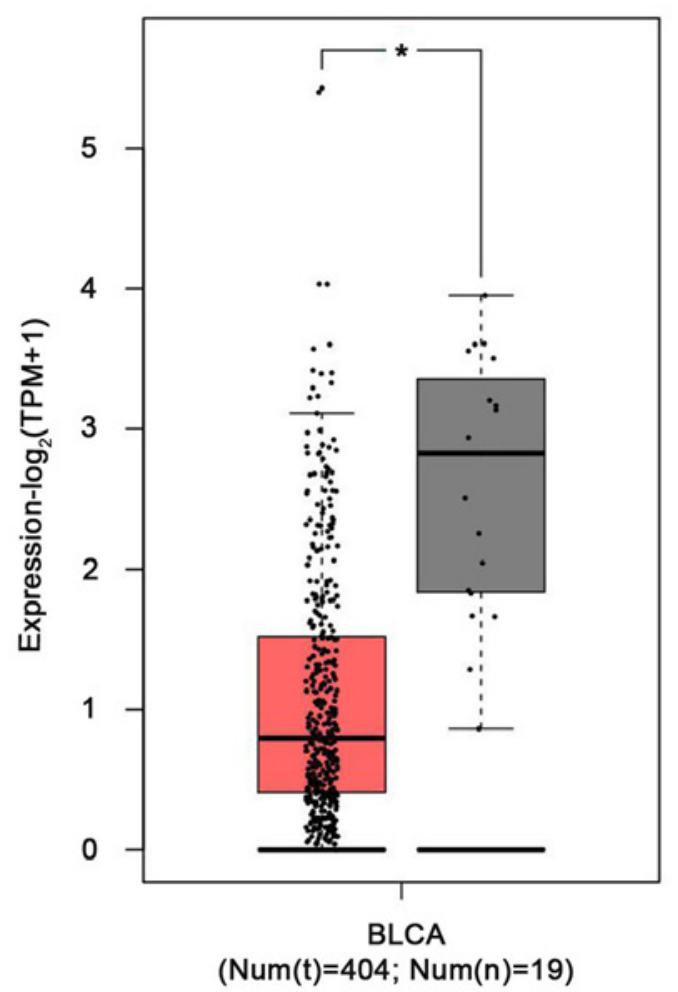

Figure 1. Identification of differentially expressed sialyl transferases in BLCA and normal tissues using TCGA and GEPIA databases. (A) Heatmap analysis of differentially expressed glycosyltransferase genes in TCGA between 19 normal and 414 BLCA tumor tissues. The red-to-blue scale is defined by $\log _{10}(X+0.001)(X:$ The amount of gene expression for counts data). (B) Volcano plot analysis of differentially expressed glycosyltransferase genes in TCGA database between 19 normal and 414 BLCA tumor tissues. $\mid \log _{2}($ fold change) $\mid>2$ and FDR $<0.001$ were set as the screening criteria. The blue and red dots represent the downregulated and upregulated genes in BLCA tumor tissues, and the grey dots represent genes that did not satisfy the screening criteria. (C) Differential expression of the ST8SIA1 gene in patients with BLCA was identified using data from the GEPIA database. *P<0.05. BLCA, bladder cancer; FDR, false discovery rate; GEPIA, Gene Expression Profiling Interactive Analysis; Num(n), number of normal tissue samples; Num(t), number of tumor tissue samples; ST8SIA1, $\alpha$-2,8-sialyltransferase1; TCGA, The Cancer Genome Atlas; TPM, transcripts per million.

the cells on the upper surface of the filter were completely removed using a cotton swab. The 24-well Transwell chambers were coated with $40 \mu 1$ Matrigel $^{\circledR}$ for $30 \mathrm{~min}$ at $37^{\circ} \mathrm{C}$ on the upward-facing side of the polycarbonate membrane for the invasion assay. Subsequently, $4 \times 10^{4}$ cells in $150 \mu 1$ serum-free medium were added to the upper chamber and $500 \mu \mathrm{l}$ medium containing $20 \%$ FBS was added into the lower chambers. After incubation for $48 \mathrm{~h}$ at $37^{\circ} \mathrm{C}$, the cells were fixed with $4 \%$ paraformaldehyde at room temperature for $15 \mathrm{~min}$ and stained with $0.1 \%$ crystal violet at room temperature for $10 \mathrm{~min}$. The cells were imaged using a light microscope and counted using ImageJ software v.4.0 (National Institutes of Health).

Statistical analysis. All experiments were repeated at least three times. Quantitative data are presented as the mean \pm SD. Statistical analysis was performed using GraphPad Prism 5.0 software (GraphPad Software, Inc.). Differences between two groups were analyzed using Student's unpaired t-test, whereas those among multiple groups were analyzed using one-way ANOVA followed by the post hoc Tukey's test. The $\chi^{2}$ test was 
A

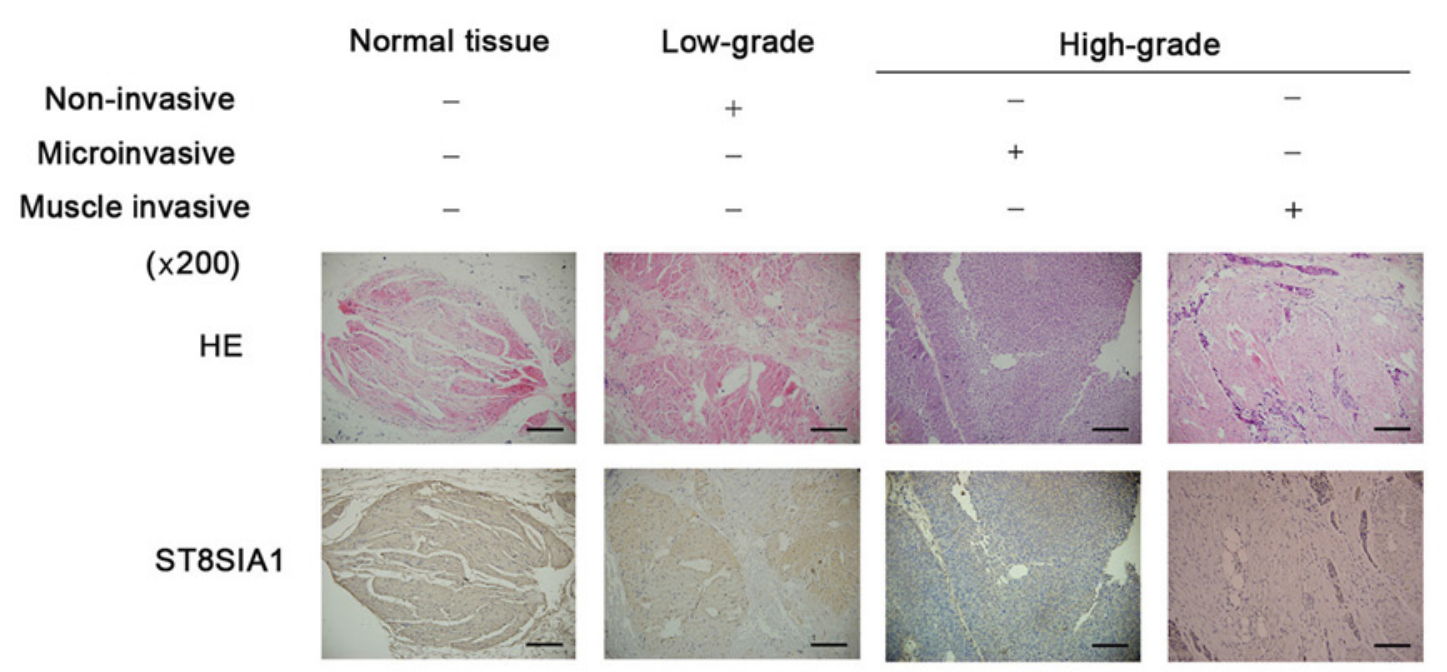

B
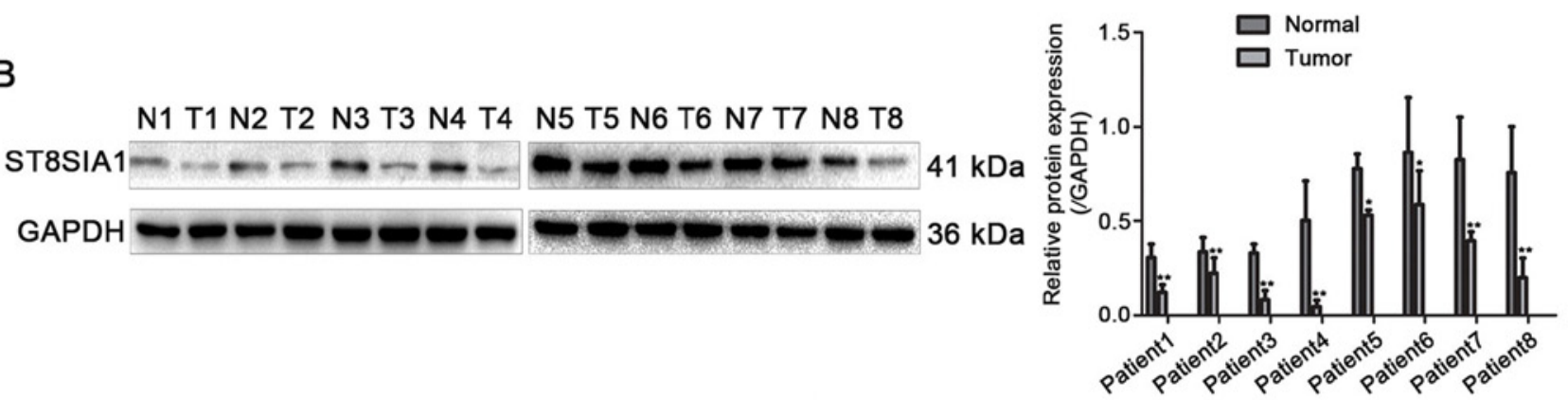

C
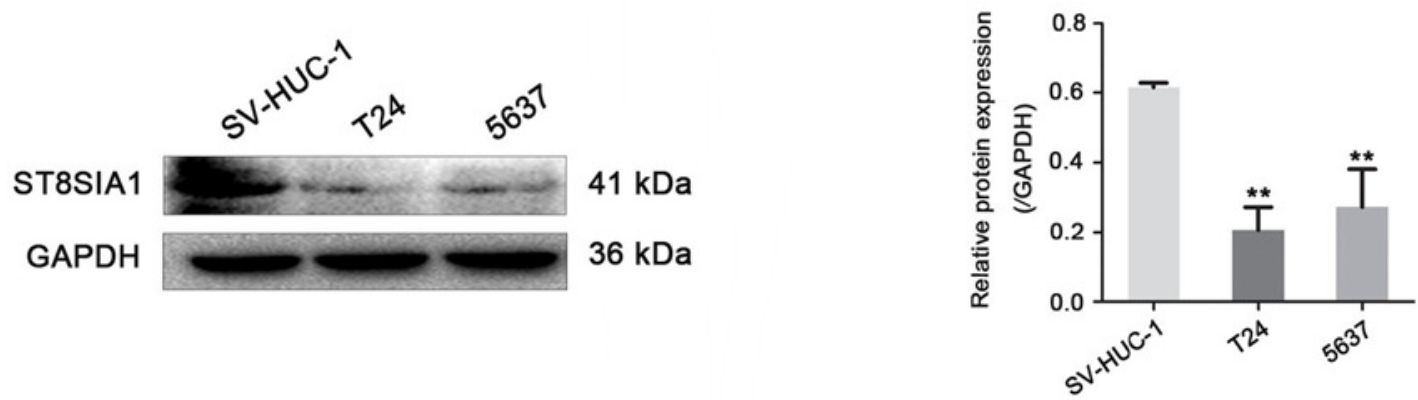

Figure 2. ST8SIA1 expression is markedly downregulated in BLCA tissues and cells. (A) Immunohistochemical staining analysis of ST8SIA1 expression in high-grade, low-grade and adjacent normal tissues. Scale bar, $250 \mu \mathrm{m}$; magnification, x200. (B) Western blot analysis of ST8SIA1 protein expression in 8 pairs of BLCA and adjacent normal tissues. GAPDH served as a control. ${ }^{*} \mathrm{P}<0.05$ and ${ }^{* *} \mathrm{P}<0.01$ vs. adjacent normal tissues. (C) ST8SIA1 protein expression was measured using western blot analysis in 5637 and T24 BLCA cell lines and the SV-HUC-1 normal bladder epithelial cell line. GAPDH served as a control. ${ }^{* *} \mathrm{P}<0.01$ vs. SV-HUC-1 cell line. BLCA, bladder cancer; N, normal; ST8SIA1, $\alpha-2,8$-sialyltransferase1; T, tumor.

performed for the comparisons of categorical variables. $\mathrm{P}<0.05$ was considered to indicate a statistically significant difference.

\section{Results}

Identification of differentially expressed STs in BLCA and normal tissues using TCGA and GEPIA databases. To identify the STs associated with the malignant progression of BLCA, TCGA (https://cancergenome.nih.gov/) was utilized to analyze the differentially expressed glycosyltransferse genes between 414 BLCA and 19 normal tissue samples. Using FDR $<0.001$ and $\mid \log _{2}($ fold change) $\mid>2$ as the selection criteria for the standardized data, 13 glycosyltransferases, including only 1 ST (ST8SIA1) with low expression levels in BLCA, were identified (Fig. 1A and B). The expression levels of ST8SIA1 were further assessed based on the data obtained from GEPIA (http://gepia.cancer-pku.cn/). Decreased ST8SIA1 expression was identified in BLCA tissues compared with normal tissues (Fig. 1C). These results suggested that ST8SIA1 may serve an important role in the development of BLCA.

ST8SIA1 expression is markedly downregulated in BLCA tissues and cells, and negatively associated with the pathological grade and invasiveness in patients with BLCA. To validate the results obtained using TCGA, immunohistochemical staining and western blot analysis were used to detect the expression levels of ST8SIA1 in BLCA. The data indicated that ST8SIA1 protein showed cytoplasm staining and the staining intensity of ST8SIA1 in high-grade cancer tissues was lower compared with that in low-grade cancer and adjacent normal tissues (Fig. 2A). 
Table I. Association between ST8SIA1 expression and clinicopathological characteristics of patients with bladder cancer.

\begin{tabular}{|c|c|c|c|c|c|}
\hline \multirow[b]{2}{*}{ Variables } & \multirow[b]{2}{*}{ No. } & \multicolumn{2}{|c|}{ ST8SIA1 expression } & \multirow[b]{2}{*}{$\chi^{2}$} & \multirow[b]{2}{*}{ P-value } \\
\hline & & $-/+, \mathrm{n}$ & $++/+++, \mathrm{n}$ & & \\
\hline \multicolumn{6}{|l|}{ Age, years } \\
\hline$\leq 50$ & 51 & 36 & 15 & 0.323 & 0.570 \\
\hline$>50$ & 85 & 56 & 29 & & \\
\hline \multicolumn{6}{|l|}{ Sex } \\
\hline Female & 39 & 25 & 14 & 0.314 & 0.575 \\
\hline Male & 97 & 67 & 30 & & \\
\hline Grade & & & & 61.710 & $<0.01$ \\
\hline Low (I/II) & 39 & 7 & 32 & & \\
\hline High (III/IV) & 97 & 85 & 12 & & \\
\hline Invasion & & & & 49.041 & $<0.01$ \\
\hline Non-invasive & 38 & 9 & 29 & & \\
\hline Microinvasive & 25 & 18 & 7 & & \\
\hline Muscle invasive & 73 & 65 & 8 & & \\
\hline
\end{tabular}

Statistical analysis was performed using a $\chi^{2}$ test. ST8SIA1, $\alpha-2,8$-sialyltransferase 1 .

The expression levels of ST8SIA1 in 8 pairs of BLCA and adjacent normal tissues were detected by western blot analysis, and the results revealed that the protein expression levels of ST8SIA1 were significantly reduced in the tumor tissue samples (Fig. 2B). Furthermore, ST8SIA1 expression was detected in two BLCA cell lines (5637 and T24) and a normal bladder epithelial cell line (SV-HUC-1). The relative protein expression levels of ST8SIA1 were significantly lower in the BLCA cell lines compared with the normal bladder epithelial cell line (Fig. 2C). The association between ST8SIA1 protein expression and major clinicopathological characteristics was further analyzed in 136 patients with BLCA. ST8SIA1 expression was negatively associated with tumor grade and invasiveness (Table I). These data indicated that ST8SIA1 may act as a tumor suppressor in BLCA progression.

ST8SIA1 inhibits the proliferation of 5637 and T24 cells. To explore the roles of ST8SIA1 in the malignant progression of BLCA cells, T24 and 5637 cell lines stably overexpressing ST8SIA1 (ST8SIA1-1 and ST8SIA1-2) were established. RT-qPCR and western blot analysis demonstrated that T24 (Fig. 3A and B, top panel) and 5637 (Fig. 3A and B, bottom panel) cell lines with a stable overexpression of ST8SIA1 were successfully constructed using molecular cloning and liposome transfection technology. To investigate the effects of ST8SIA1 upregulation on the proliferation and colony formation of BLCA cells, CCK-8, colony formation and flow cytometry assays were performed. The CCK- 8 assay revealed that the proliferation of T24 (Fig. 3C, left panel) and 5637 (Fig. 3C, right panel) cells stably overexpressing ST8SIA1 (ST8SIA1-1 and ST8SIA1-2) was significantly reduced compared with that of mock and non-transfected cells. To further confirm this result, a colony formation assay was performed and demonstrated that ST8SIA1 overexpression decreased the number of T24 (Fig. 3D, top panel) and 5637 (Fig. 3D, bottom panel) cell colonies. The flow cytometry results revealed that ST8SIA1 overexpression markedly arrested T24 (Fig. 3E, top panel) and 5637 (Fig. 3E, bottom panel) cells in the $\mathrm{S}$ phase of the cell cycle. These results suggested that ST8SIA1 downregulated the proliferation ability of 5637 and T24 cells.

ST8SIA1 inhibits the migration and invasion of 5637 and T24 cells. To further verify the effects of ST8SIA1 on the malignant progression of BLCA cells, wound healing and Transwell assays were used to analyze migration and invasion following ST8SIA1 overexpression in 5637 and T24 cells. The results of the wound healing assay demonstrated that the motility of T24 (Fig. 4A, top panel) and 5637 (Fig. 4A, bottom panel) cells stably overexpressing ST8SIA1 (ST8SIA1-1 and ST8SIA1-2) was markedly reduced compared with that of mock and non-transfected cells within $12 \mathrm{~h}$. Furthermore, the frequencies of T24 (Fig. 4B and C, top panel) and 5637 (Fig. 4B and C, bottom panel) cells that migrated and invaded into the lower chamber were significantly decreased following ST8SIA1 overexpression. These data indicated that ST8SIA1 attenuated the migration and invasion ability of 5637 and T24 cells.

ST8SIA1 suppresses the JAK2/STAT3 signaling pathway in 5637 and T24 cells. To explore the molecular mechanisms of the antitumor effect of ST8SIA1 in BLCA cells, the activation and expression levels of JAK/STAT, as well as the involved signaling molecules were detected by western blot analysis in 5637 and T24 cells following ST8SIA1 overexpression. The results demonstrated that ST8SIA1 overexpression in T24 (Fig. 5A) and 5637 (Fig. 5B) cells markedly reduced the ratio of the phosphorylated JAK2/total JAK2 and the phosphorylated STAT3/total STAT3, as well as the expression levels of the downstream targets of JAK/STAT signaling pathway, such as MMP2, PCNA, cyclin D1 and Bcl2 compared with mock and non-transfected cells. These results suggested that 

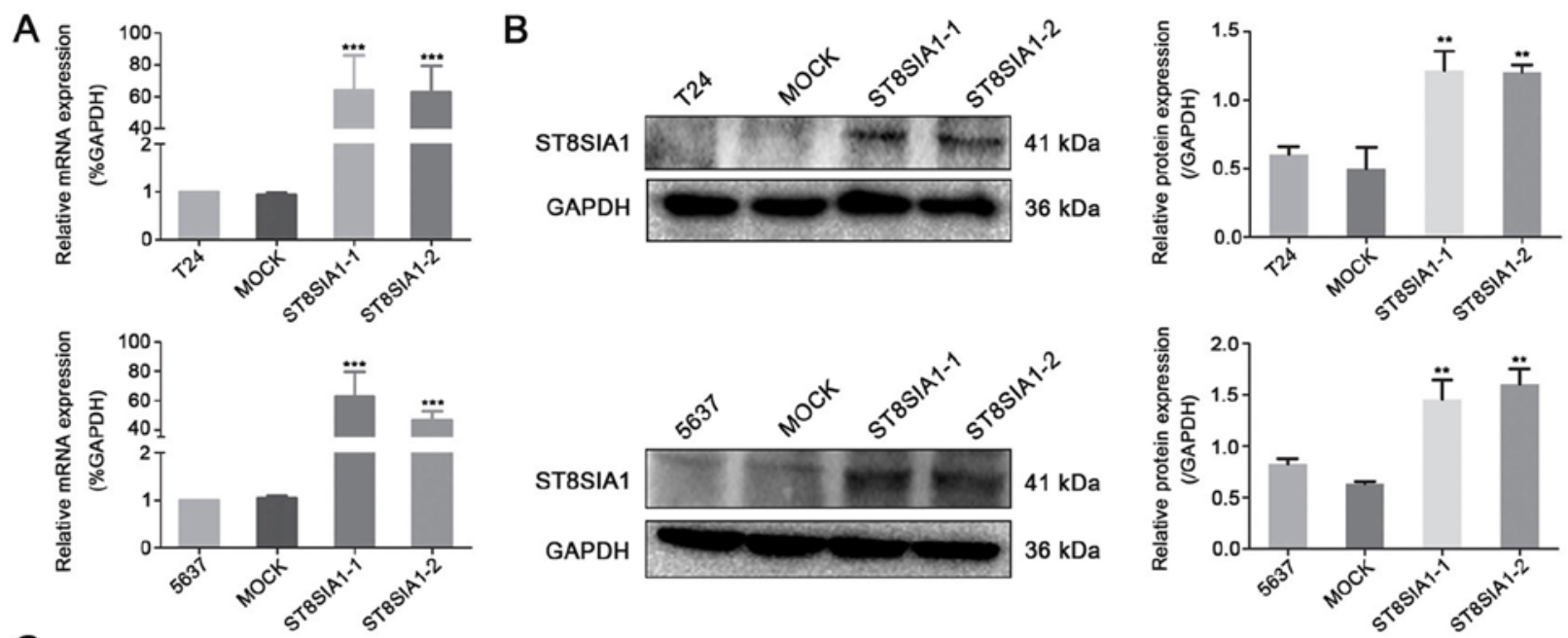

C
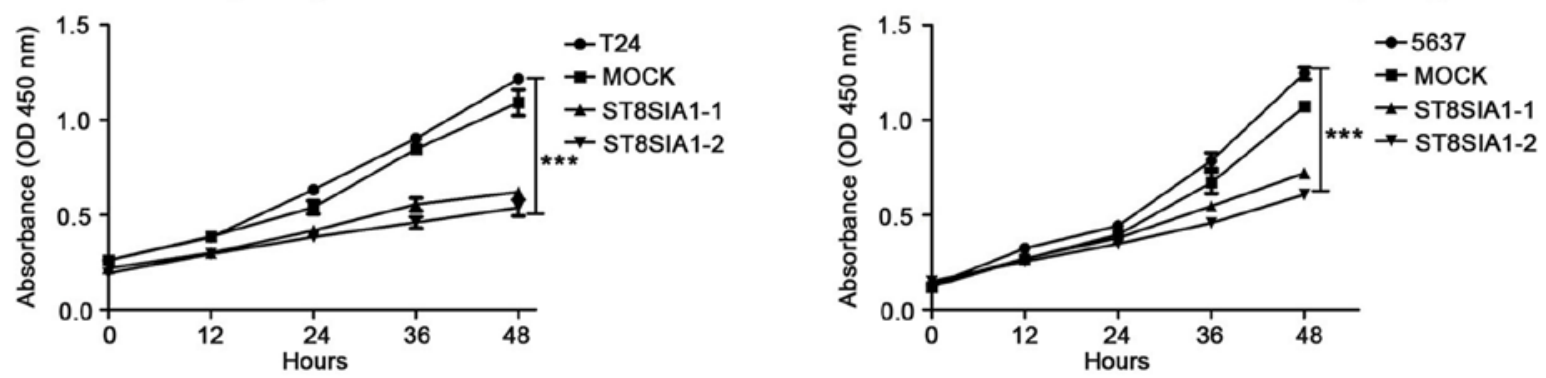

D

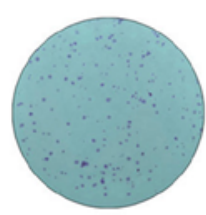

T24

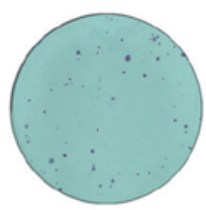

5637

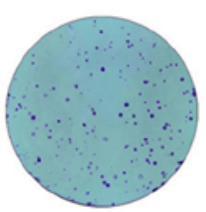

MOCK

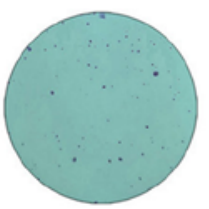

MOCK

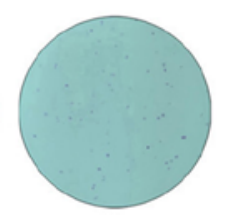

ST8SIA1-1

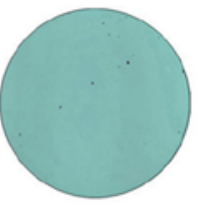

ST8SIA1-1
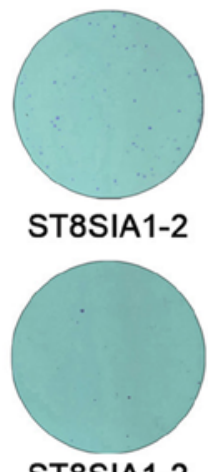

ST8SIA1-2
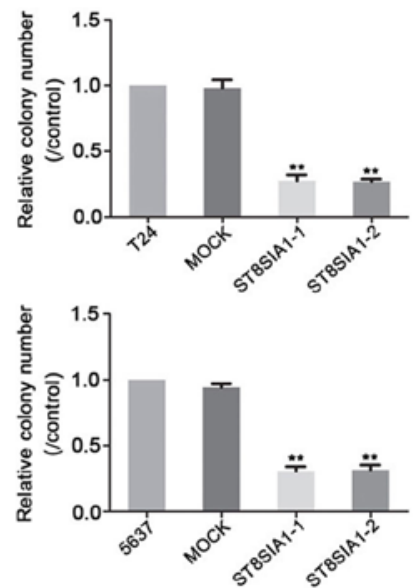

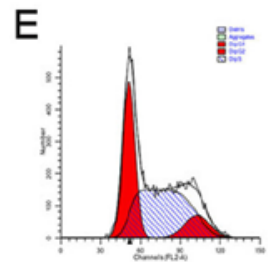

T24

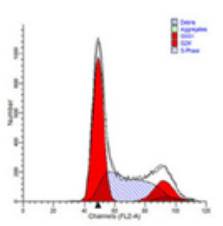

5637

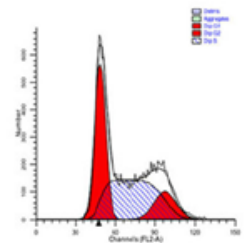

MOCK

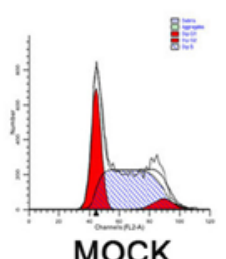

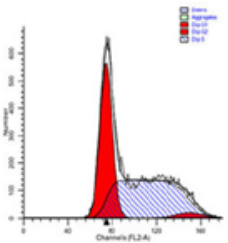

ST8SIA1-1

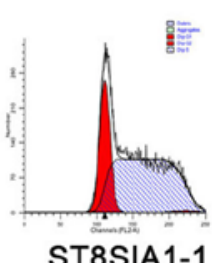

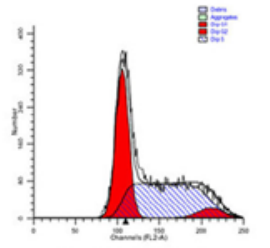

ST8SIA1-2

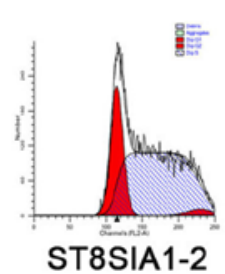

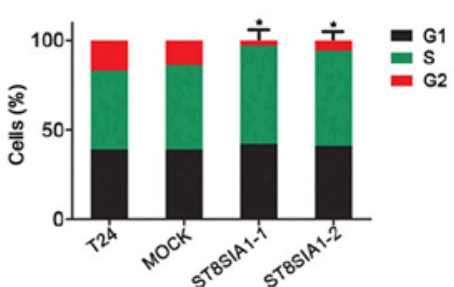

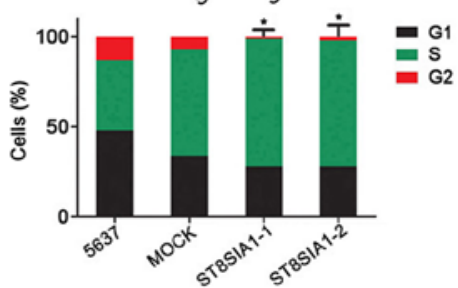

Figure 3. ST8SIA1 inhibits the proliferation of 5637 and T24 cells. (A) Reverse transcription-quantitative PCR analysis ofST8SIA1 mRNA expression in non-transfected T24 or 5637 cells, mock and stably transfected cells (ST8SIA1-1 and ST8SIA1-2). Relative changes in gene expression were normalized to GAPDH and analyzed using the $2^{-\Delta \Delta \mathrm{Cq}}$ method. ${ }^{* * *} \mathrm{P}<0.001$ vs. mock. (B) Western blot analysis of ST8SIA1 protein expression in non-transfected T24 or 5637, mock, ST8SIA1-1 and ST8SIA1-2 cells. GAPDH served as a control. ${ }^{* *} \mathrm{P}<0.01$ vs. mock. (C) Proliferation of non-transfected T24 or 5637 cells, mock, ST8SIA1-1 and ST8SIA1-2 cells was detected using a Cell Counting Kit- 8 assay at 0, 12, 24, 36 and 48 h. ${ }^{* * *} \mathrm{P}<0.001$ vs. mock. (D) The clonogenic ability of non-transfected T24 or 5637, mock, ST8SIA1-1 and ST8SIA1-2 cells was analyzed using a cell colony formation assay (magnification, $\mathrm{x} 100$ ). ${ }^{* *} \mathrm{P}<0.01$ vs. mock. (E) Flow cytometry was used to analyze the cell cycle of non-transfected T24 or 5637, mock, ST8SIA1-1 and ST8SIA1-2 cells. "P<0.05 vs. mock. OD, optical density; ST8SIA1, $\alpha-2,8$-sialyltransferase1. 
A
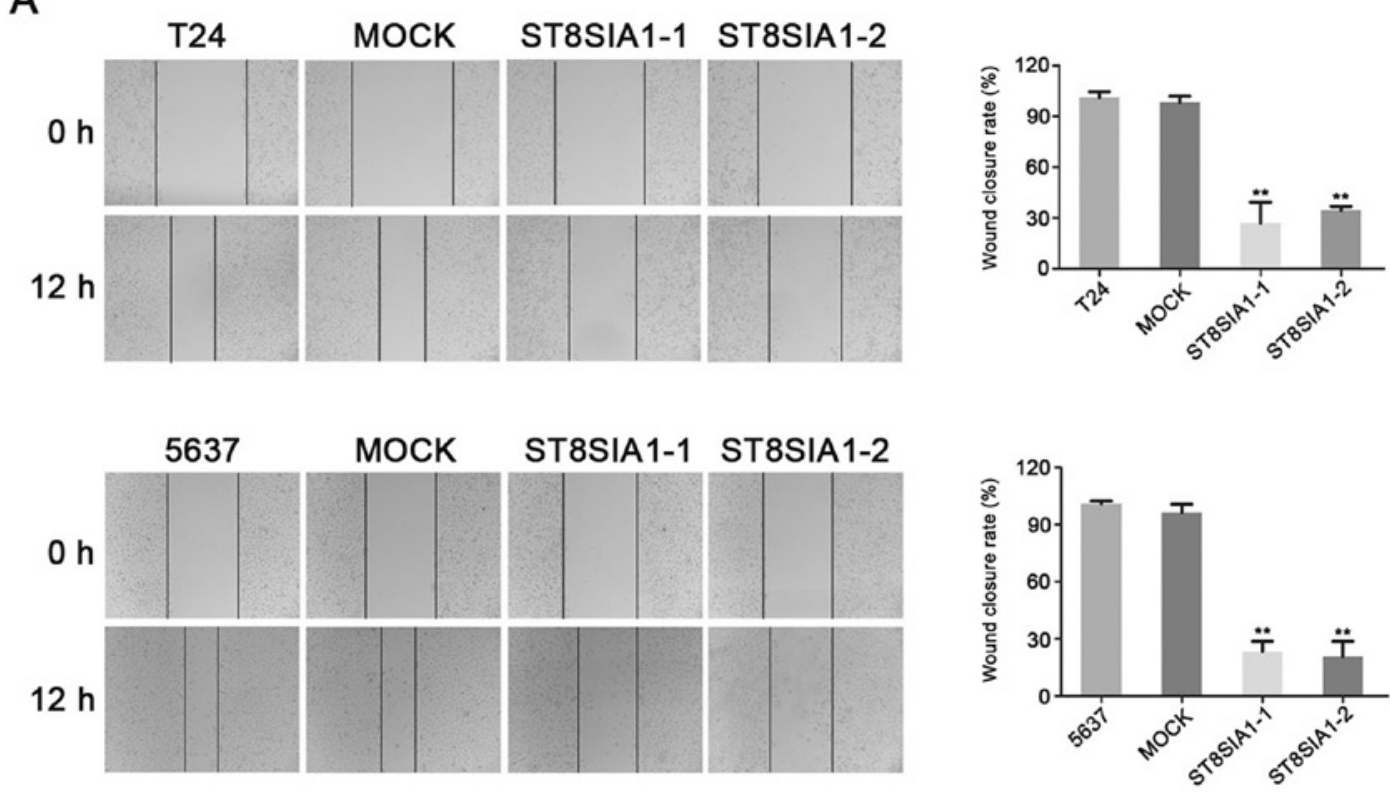

B
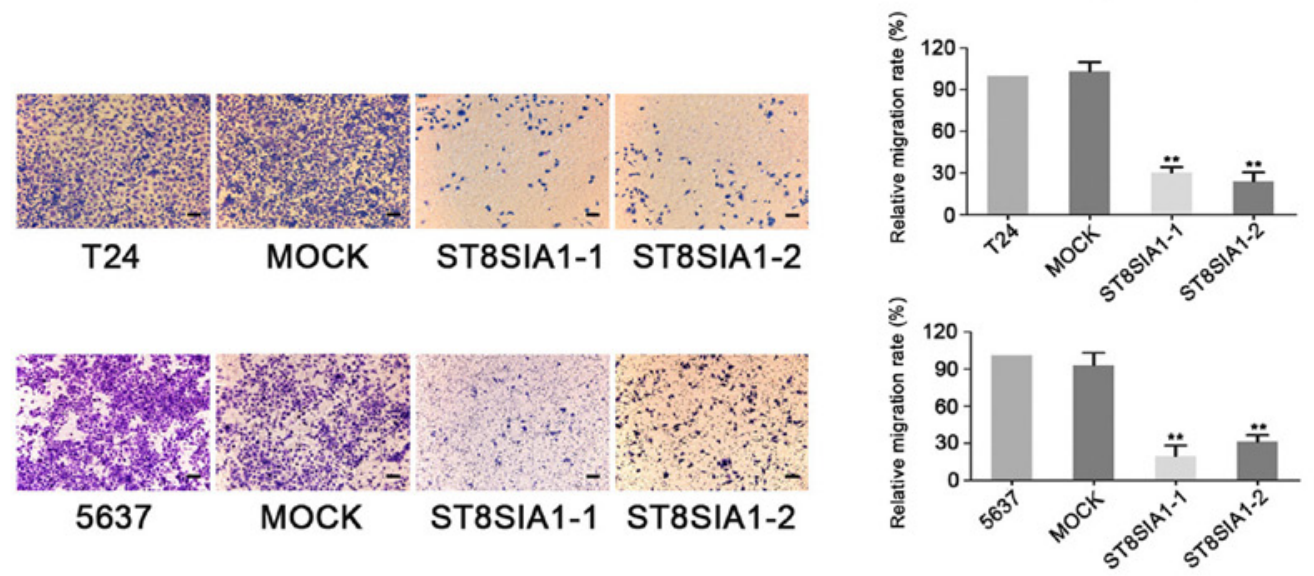

C
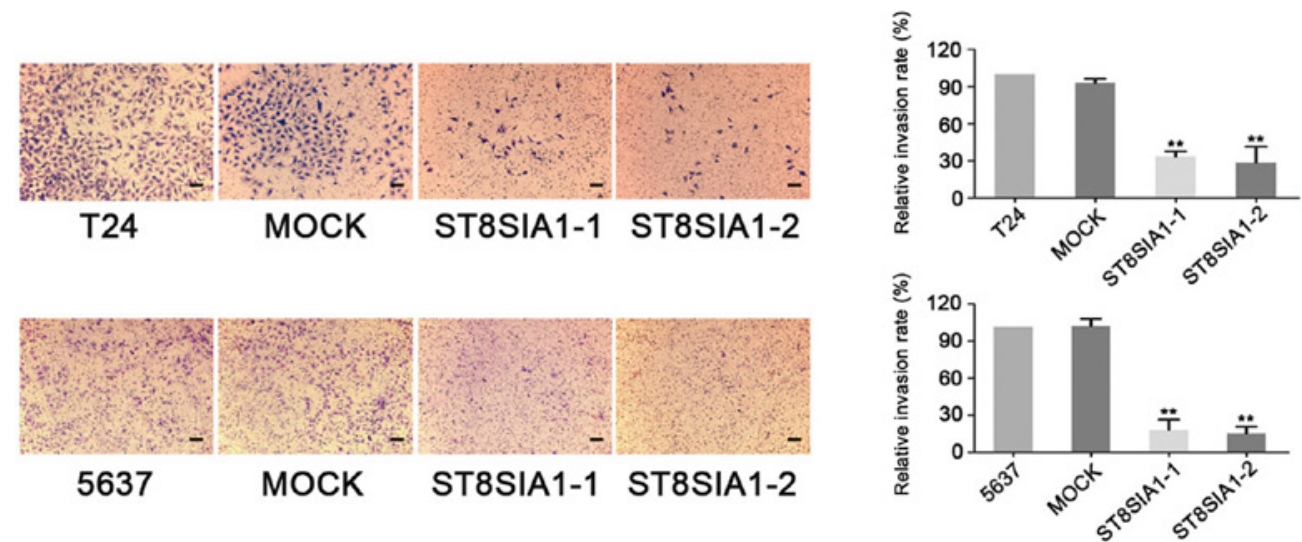

Figure 4. ST8SIA1 inhibits the migration and invasion of 5637 and T24 cells. (A) A wound healing assay was used to analyze the motility of non-transfected T24 or 5637, mock, ST8SIA1-1 and ST8SIA1-2 cells (magnification, x200). ${ }^{* *} \mathrm{P}<0.01$ vs. mock. (B) Migratory properties of non-transfected T24 or 5637, mock, ST8SIA1-1 and ST8SIA1-2 cells were evaluated using a Transwell migration assay. Scale bar, $400 \mu \mathrm{m} .{ }^{* *} \mathrm{P}<0.01$ vs. mock. (C) Invasion properties of the cells were evaluated using a Transwell assay. Scale bar, $400 \mu \mathrm{m}$. ${ }^{* *} \mathrm{P}<0.01$ vs. mock. ST8SIA1, $\alpha-2,8$-sialyltransferase1.

ST8SIA1 inhibited the activation of JAK2/STAT3 signaling pathway.

\section{Discussion}

Sialylation is the process of adding sialic acid to the ends of oligosaccharides and glycoproteins by STs and glycosidase.
Sialylation is involved in embryonic development, reprogramming, tumorigenesis and immune response (21). Elevated mRNA expression levels of ST3GAL2 and ST3GAL3 have been reported to serve an important role in the progression and metastasis of oral cancer (22). Glycoproteins carrying ST3GAL4 have been identified in gastric cancer cells overexpressing sialyl Lewis $\mathrm{x}$, and the potential of these 
A

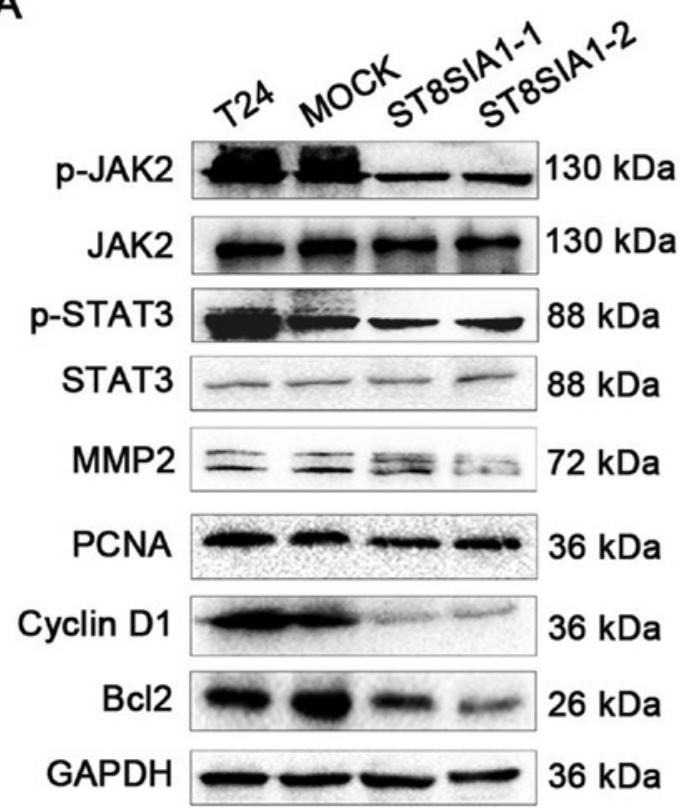

B

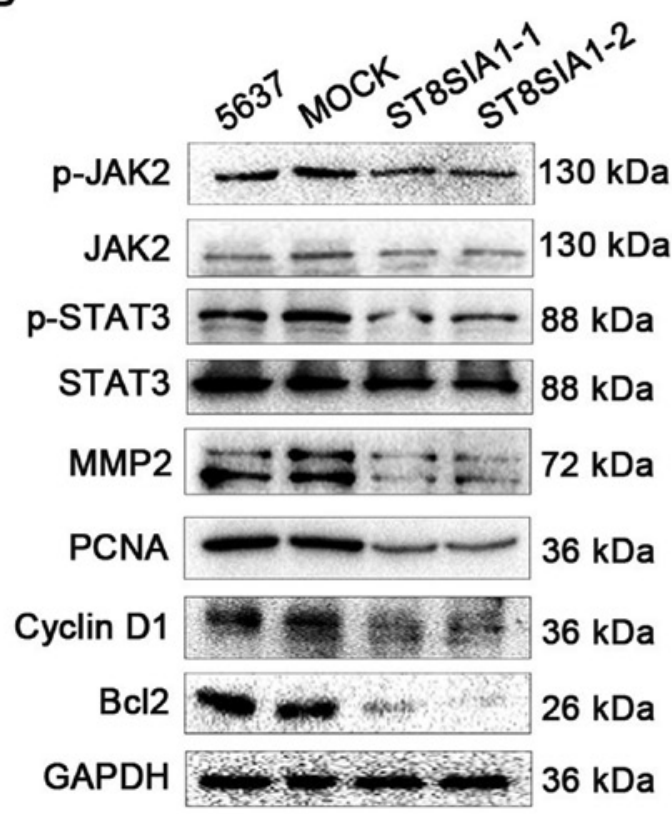

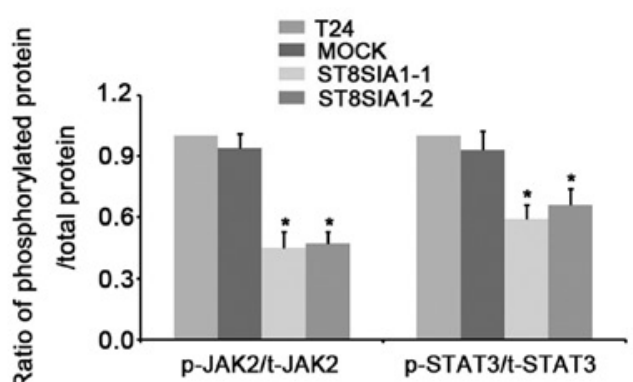
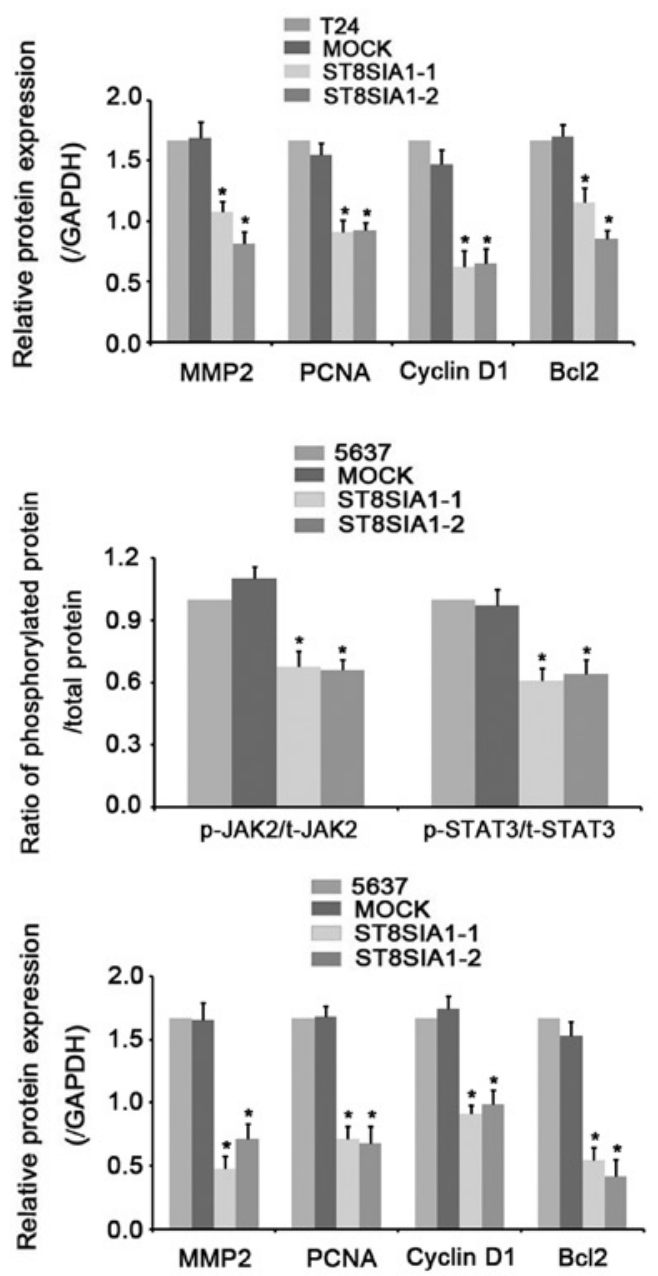

Figure 5. ST8SIA1 suppresses the JAK2/STAT3 signaling pathway in 5637 and T24 cells. (A) Western blot analysis of the phosphorylation levels of JAK2 and STAT3, and protein expression levels of JAK2, STAT3, MMP2, PCNA, cyclin D1 and Bcl2 in non-transfected T24, mock, ST8SIA1-1 and ST8SIA1-2 cells. GAPDH served as a control. "P<0.05 vs. mock. (B) Western blot analysis of the protein expression levels of phosphorylated JAK2, phosphorylated STAT3, JAK2, STAT3, MMP2, PCNA, cyclin D1 and Bcl2 in non-transfected 5637, mock, ST8SIA1-1 and ST8SIA1-2 cells. GAPDH served as a control. "P<0.05 vs. mock. JAK2, Janus kinase 2; p-, phosphorylated; PCNA, proliferating cell nuclear antigen; ST8SIA1, $\alpha$-2,8-sialyltransferase 1.

proteins as biomarkers of gastric cancer was evaluated (23). Zhang et al (24) reported that high expression levels of ST3GAL3 are associated with an increased resistance of ovarian cancer cells to paclitaxel, and that the downregulation of ST3GAL3 could lead to paclitaxel-induced apoptosis. A previous study had demonstrated that caveolin-1 could upregulate $\alpha 2,6$-sialylation on integrin $\alpha 5 \beta 1$, and promote integrin $\alpha 5 \beta 1$-dependent hepatocarcinoma cell adhesion (25). These results indicated that it is necessary to investigate the roles and mechanisms of various members of the ST family in various types of cancer.
Abnormal expression of STsis involved in the regulation of the malignant progression of cancer (26). Accumulating evidence has demonstrated that ST8SIA1 can influence the growth and metastasis of a number of cancer types, including triple-negative breast cancer (18), colorectal cancer (27) and cervical cancer (28). In the present study, 13 differentially expressed glycosyltransferase genes were screened using TCGA; however, only 1 ST, ST8SIA1, was identified to exhibit low expression levels in BLCA. The data obtained from the GEPIA database indicated that the mRNA expression levels of ST8SIA1 were decreased in BLCA tissues compared with 
in normal bladder tissues. The downregulation of ST8SIA1 was also validated in BLCA tissues and cells by immunohistochemistry and western blotting, respectively. However, to the best of our knowledge, the clinical significance of ST8SIA1 expression and its association with clinicopathological characteristics in patients with BLCA has not yet been determined. In the present study, clinical data from 136 patients with BLCA revealed that ST8SIA1 was negatively associated with the pathological grade and degree of invasion of BLCA. These results suggested that ST8SIA1 may act as a tumor suppressor in BLCA.

ST8SIA1 is a key enzyme that converts monosialoganglioside-3 (GM3) to disialoganglioside-3 (GD3) (29). ST8SIA1 can protect nerves from GD3-mediated apoptosis (30). Mandal et al (31) have reported that ST8SIA1 overexpression can inhibit the growth of neovascularization cells and block cells at the $\mathrm{S}$ phase of the cell cycle to induce apoptosis in pancreatic cancer cells. In the present study, to investigate the roles of ST8SIA1 in the malignant progression of BLCA, two BCLA cell lines (T24 and 5637) stably overexpressing ST8SIA1 were established. Functional assays indicated that the overexpression of ST8SIA1 inhibited the proliferation, migration and invasion of BLCA cells, suggesting that ST8SIA1 may have an inhibitory effect on the malignant behavior of BLCA cells. It was suggested that this phenomenon may be due to the methylation of the ST8SIA1 gene in the development of BLCA, with the subsequent inhibition of ST8SIA1 expression and activity in tumor cells (32).

The abnormal activation of JAK/STAT signaling is a key factor contributing to tumor growth and metastasis (33). To explore the molecular mechanism of the effect of ST8SIA1 on the occurrence and development of BLCA, the association between ST8SIA1 and the JAK/STAT signaling pathway was detected. The results demonstrated that ST8SIA1 overexpression inhibited the phosphorylation of JAK2 and STAT3 but did not affect their protein expression. The protein expression levels of JAK/STAT pathway-targeting signaling molecules, such as MMP2, PCNA, cyclin D1 and Bcl2, were markedly reduced following ST8SIA1 upregulation. These findings suggested that ST8SIA1 may attenuate the proliferation and metastasis of BLCA by suppressing the JAK-STAT signaling pathway. Wang et al (34) reported that GM3 inhibited the adhesion, proliferation and EGFR phosphorylation of YTS-1, T24, 5637 and KK47 human BLCA cell lines. Therefore, it was suggested that ST8SIA1 may decrease the phosphorylation of EGFR, JAK2 and STAT3 by increasing the sialylation of GM3. However, the detailed molecular mechanism requires additional studies and verification.

In conclusion, to the best of our knowledge, the present study was the first to report that ST8SIA1 expression was reduced in human BLCA tissue and cell lines. The expression levels of ST8SIA1 in human BLCA tissue were negatively associated with the pathological grade and invasiveness of BLCA. Furthermore, the present study provided evidence that ST8SIA1 could decrease the proliferation, migration and invasion of BLCA cells by blocking the activation of JAK/STAT signaling and downregulating the expression levels of JAK/STAT pathway-targeting signaling molecules. The expression pattern and antitumor role of ST8SIA1 in BLCA suggested that ST8SIA1 should be further evaluated as a potential candidate target for the diagnosis and treatment of BLCA.

\section{Acknowledgements}

Not applicable.

\section{Funding}

The present study was supported by the Project of Education Department in Liaoning Province (grant no. LNSJYT201917) and Natural Science Foundation of Liaoning Province (grant no. 2019-ZD-0640).

\section{Availability of data and materials}

The datasets used and/or analyzed during the current study are available from the corresponding author on reasonable request.

\section{Authors' contributions}

SY, SW and XS analyzed and interpreted the data. SY, SW, XS, YW, JZ and JL performed the experiments and analyzed the data. SY and SW wrote the manuscript. DY and YJ edited and revised the manuscript. DY and YJ proposed the conception of the study and designed the project. SY, XS and YJ confirmed the authenticity of all the raw data. All authors read and approved the final manuscript.

\section{Ethics approval and consent to participate}

The present study was approved by the Institutional Research Ethics Committee of the First Affiliated Hospital of Dalian Medical University (approval no. LCKY2015-08; Dalian, China), and written informed consent was provided by the patients with bladder cancer who underwent surgery.

\section{Patient consent for publication}

Not applicable.

\section{Competing interests}

The authors declare that they have no competing interests.

\section{References}

1. Bray F, Ferlay J, Soerjomataram I, Siegel RL, Torre LA and Jemal A: Global cancer statistics 2018: GLOBOCAN estimates of incidence and mortality worldwide for 36 cancers in 185 countries. CA Cancer J Clin 68: 394-424, 2018

2. Ohadian Moghadam S and Nowroozi MR: Toll-like receptors: The role in bladder cancer development, progression and immunotherapy. Scand J Immunol 90: e12818, 2019.

3. Tan TZ, Mathieu R, Tan KT, Huang YJ and Jean-Paul T: Molecular subtypes of urothelial bladder cancer: Results from a meta-cohort analysis of 2411 Tumors. Eur Urol 75: 423-432, 2019.

4. McConkey DJ and Lerner SP: SIU-ICUD consultation on bladder cancer: Basic science. World J Urol 37: 15-29, 2019.

5. Moremen KW, Tiemeyer M and Nairn AV: Vertebrate protein glycosylation: Diversity, synthesis and function. Nat Rev Mol Cell Biol 13: 448-462, 2012.

6. Tang L, Chen X, Zhang X, Guo Y, Su J, Zhang J, Peng C and Chen X: N-Glycosylation in progression of skin cancer. Med Oncol 36: 50, 2019.

7. Silsirivanit A: Glycosylation markers in cancer. Adv Clin Chem 89: 189-213, 2019. 
8. Munkley J: Glycosylation is a global target for androgen control in prostate cancer cells. Endocr Relat Cancer 24: R49-R64, 2017.

9. Hoja-Lukowicz D, Przybylo M, Duda M, Pochec E and Bubka M: On the trail of the glycan codes stored in cancer-related cell adhesion proteins. Biochim Biophys Acta Gen Subj 1861: 3237-3257, 2017.

10. Vajaria BN and Patel PS: Glycosylation: A hallmark of cancer? Glycoconj J 34: 147-156, 2017.

11. Veillon L, Fakih C, Abou-El-Hassan H, Kobeissy F and Mechref Y: Glycosylation changes in brain cancer. ACS Chem Neurosci 9: 51-72, 2018.

12. Natoni A, Bohara R, Pandit A and O'Dwyer M: Targeted approaches to inhibit sialylation of multiple myeloma in the bone marrow microenvironment. Front Bioeng Biotechnol 7: 252, 2019.

13. Natoni A, Macauley MS and O'Dwyer ME: Targeting selectins and their ligands in cancer. Front Oncol 6: 93, 2016.

14. Weijers CA, Franssen MC and Visser GM: Glycosyltransferasecatalyzed synthesis of bioactive oligosaccharides. Biotechnol Adv 26: 436-456, 2008

15. Li Y and Chen X: Sialic acid metabolism and sialyltransferases: Natural functions and applications. Appl Microbiol Biotechnol 94: 887-905, 2012.

16. Bhide GP and Colley KJ: Sialylation of N-glycans: Mechanism cellular compartmentalization and function. Histochem Cell Biol 147: 149-174, 2017.

17. Park HJ, Kim JH, Yoon JS, Choi YJ, Choi YH, Kook KH and Choi JH: Identification and functional characterization of ST3GAL5 and ST8SIA1 variants in patients with thyroid-associated ophthalmopathy. Yonsei Med J 58: 1160-1169, 2017.

18. Nguyen K, Yan Y, Yuan B, Dasgupta A, Sun J, Mu H, Do KA Ueno NT, Andreeff M and Battula VL: ST8SIA1 regulates tumor growth and metastasis in TNBC by activating the FAK-AKT-mTOR signaling pathway. Mol Cancer Ther 17: 2689-2701, 2018.

19. Charlton ME, Adamo MP, Sun L and Deorah S: Bladder cancer collaborative stage variables and their data quality, usage, and clinical implications: A review of SEER data, 2004-2010. Cancer 120 (Suppl 23): 3815-3825, 2014.

20. Livak KJ and Schmittgen TD: Analysis of relative gene expression data using real-time quantitative PCR and the 2(-Delta Delta C(T)) method. Methods 25: 402-408, 2001.

21. Li F and Ding J: Sialylation is involved in cell fate decision during development, reprogramming and cancer progression. Protein Cell 10: 550-565, 2019.

22. Mehta KA, Patel KA, Pandya SJ and Patel PS: 'Aberrant sialylation plays a significant role in oral squamous cell carcinoma progression'. J Oral Pathol Med 49: 253-259, 2020.

23. Gomes C, Almeida A, Barreira A, Calheiros J, Pinto F, Abrantes R, Costa A, Polonia A, Polonia A, Osório $\mathrm{H}$, et al: Carcinoembryonic antigen carrying $\mathrm{SLe}^{\mathrm{x}}$ as a new biomarker of more aggressive gastric carcinomas. Theranostics 9: 7431-7446, 2019.
24. Zhang X, Yang X, Chen M, Zheng S, Li J, Lin S and Wang X: ST3Gal3 confers paclitaxel-mediated chemoresistance in ovarian cancer cells by attenuating caspase- $8 / 3$ signaling. Mol Med Rep 20: 4499-4506, 2019.

25. Yu S, Fan J, Liu L, Zhang L, Wang S and Zhang J: Caveolin-1 up-regulates integrin $\alpha 2,6$-sialylation to promote integrin a5 31 -dependent hepatocarcinoma cell adhesion. FEBS Lett 587: 782-787, 2013

26. Ghosh S: Sialylation and sialyltransferase in insects. Glycoconj J 35: 433-441, 2018.

27. Shan Y, Liu Y, Zhao L, Liu B, Li Y and Jia L: MicroRNA-33a and let-7e inhibit human colorectal cancer progression by targeting ST8SIA1. Int J Biochem Cell Biol 90: 48-58, 2017.

28. Danolic D, Heffer M, Wagner J, Skrlec I, Alvir I, Mamic I, Susnjar L, Banovic M, Danolić D and Puljiz M: Role of ganglioside biosynthesis genetic polymorphism in cervical cancer development. J Obstet Gynaecol 40: 1127-1132, 2020.

29. Yeh SC, Wang PY, Lou YW, Khoo KH, Hsiao M, Hsu TL and Wong CH: Glycolipid GD3 and GD3 synthase are key drivers for glioblastoma stem cells and tumorigenicity. Proc Natl Acad Sci USA 113: 5592-5597, 2016.

30. Bernardo A, Harrison FE, McCord M, Zhao J, Bruchey A, Davies SS, Jackson Roberts L II, Mathews PM, Matsuoka Y, Ariga T, et al: Elimination of GD3 synthase improves memory and reduces amyloid-beta plaque load in transgenic mice. Neurobiol Aging 30: 1777-1791, 2009.

31. Mandal C, Sarkar S, Chatterjee U, Schwartz-Albiez R and Mandal C: Disialoganglioside GD3-synthase over expression inhibits survival and angiogenesis of pancreatic cancer cells through cell cycle arrest at S-phase and disruption of integrin- 31 -mediated anchorage. Int J Biochem Cell Biol 53: 162-173, 2014.

32. Weisenberger DJ: Characterizing DNA methylation alterations from the cancer genome atlas. J Clin Invest 124: 17-23, 2014.

33. Arumuggam N, Bhowmick NA and Rupasinghe HP: A Review: Phytochemicals targeting JAK/STAT signaling and IDO expression in cancer. Phytother Res 29: 805-817, 2015.

34. Wang H, Isaji T, Satoh M, Li D, Arai Y and Gu J: Antitumor effects of exogenous ganglioside GM3 on bladder cancer in an orthotopic cancer model. Urology 81: 210.e11-5, 2013.

This work is licensed under a Creative Commons Attribution-NonCommercial-NoDerivatives 4.0 International (CC BY-NC-ND 4.0) License. 